\title{
Treatment of Gram-negative infections in patients before and after renal transplantation
}

\author{
D. A. LEIGH* \\ M.B., B.S. \\ Lecturer in Microbiology, The Wright-Fleming Institute, \\ St Mary's Hospital Medical School, London
}

\begin{abstract}
Summary
Sixty-six Gram-negative infections, occurring in thirty-four patients before and after human cadaveric renal transplantation, were treated with either gentamicin or carbenicillin. All patients were difficult chemotherapeutic problems and many were receiving immunosuppressive therapy. The majority of the infections occurred either in the urinary tract or in the peritoneal cavity following dialysis.
\end{abstract}

Laboratory studies with gentamicin showed that $98 \%$ of the strains of Gram-negative bacilli from this group of patients were sensitive to $5 \mu \mathrm{g} / \mathrm{ml}$. Seventy-seven per cent of all Gram-negative bacilli were sensitive to $100 \mu \mathrm{g} / \mathrm{ml}$ of carbenicillin.

The outcome of treatment was found to depend on the presence of an underlying abnormality. An overall cure rate of $75 \%$ was achieved in simple infections but where the infection was complicated by an underlying abnormality the rate fell to $45 \%$ and reinfection was very common (67\%). There was no significant difference in the cure rate obtained with gentamicin or carbenicillin.

Acute toxic effects due to gentamicin were seen in one case but many patients died before assessment was possible. No toxic effects were seen with carbenicillin treatment but intramuscular injections often caused local pain.

Gentamicin and carbenicillin are two valuable additions to the antibiotics available for the treatment of Gram-negative infections. The success of treatment in these infections, however, will depend on the accessibility of the primary focus of infection to the antibiotic and the nature of the underlying abnormality.

\section{Introduction}

The susceptibility to infection of patients undergoing renal transplantation has been reported in many studies and the use of steroid and immuno-

\footnotetext{
* Present address: Consultant Bacteriologist, Department of Pathology, High Wycombe General Hospital, High Wycombe, Bucks.
}

suppressive therapy is undoubtedly an important factor in the development of the infection. The bacteria associated with these infections are predominantly strains of the Enterobacteriaciae and Pseudomonas aeruginosa which show multiple resistance to antibiotics.

Within the last few years two antibiotics with greater activity against the resistant strains of Gramnegative bacilli have been developed.

In 1963 Weinstein et al. described the discovery of a new basic, water-soluble antibiotic, gentamicin which had been isolated from Micromonospora purpurea. This substance contains a 2-deoxystreptamine component, is chemically related to the streptomycin group of antibiotics (Rosselet et al., 1963) and has been shown to be bactericidal against a wide range of antibiotic-resistant bacteria (Barber \& Waterworth, 1966).

In 1967 a new semisynthetic penicillin, carbenicillin was described (Knudsen, Rolinson \& Sutherland, 1967) which had greater activity against $P$. aeruginosa and the resistant strains of Proteus than previous penicillin compounds (Brumfitt, Percival \& Leigh, 1967).

In this paper the result of treating sixty-six infections in thirty-four patients with these two antibiotics before and after the transplantation of cadaver kidneys is reported. All patients were difficult chemotherapeutic problems as the majority had suffered from recurrent infections and had severe underlying abnormalities and many were on immunosuppressive therapy.

\section{The patients}

The details of the patients treated with gentamicin and carbenicillin are shown in Table 1 . The patients were selected because they had infections due to Gram-negative bacilli which either showed multiple resistance to antibiotics or had failed to respond to previous antibiotic therapy. No attempt was made to compare the results of treatment with the two antibiotics as in a controlled trial and the infections 
TABLE 1. Details of the thirty-four patients treated with gentamicin or carbenicillin

\begin{tabular}{lcc}
\hline & Gentamicin & Carbenicillin \\
\hline No of patients treated & 24 & 20 \\
Sex & & \\
$\quad$ Male & 10 & 13 \\
$\quad$ Female & 14 & 7 \\
Age (years) & & \\
$\quad$ Average & 33 & 31 \\
$\quad$ Range & $16-49$ & $12-47$ \\
No. patients who received & & \\
$\quad$ renal transplants & 16 & 15 \\
No. infections treated & 39 & 27 \\
$\quad$ Pre-transplantation & 11 & 8 \\
$\quad$ Post-transplantation & 28 & 19 \\
\hline
\end{tabular}

* Ten patients received courses of both gentamicin and carbenicillin for different episodes of infection.

were only similar in that they occurred in the same group of patients.

Thirty-four patients were treated; fourteen received only gentamicin, ten received only carbenicillin and ten received courses of both gentamicin and carbenicillin for different episodes of infection.

There was no significant difference in the age or number of patients in the two treatment groups. The proportion of infections occurring before and after renal transplantation was similar in the two groups.

The sites of the sixty-six infections and the causative organisms are shown in Table 2. The majority of infections were of the urinary tract or the peritoneal cavity following dialysis and the most common organism was Ps. aeruginosa. Nine infections, five treated with gentamicin and four with carbenicillin were complicated by bacteraemia. In six cases the primary site of infection was the urinary tract, and in three cases it was the peritoneal cavity.

\section{Criteria of infection}

Urinary tract infection was considered to be present when 100,000 organisms $/ \mathrm{ml}$ of a single bacterial species were found in two consecutive daily specimens of urine. Infection of the peritoneal cavity was diagnosed when an organism was isolated from two consecutive specimens of dialysis fluid. The presence of lung infection was detected by the examination of a Gram-stained film of the sputum for white cells and bacteria which were subsequently confirmed by culture.

\section{Laboratory methods}

All specimens were examined immediately on arrival at the laboratory or were stored at $4^{\circ} \mathrm{C}$ until examination was possible.

Urines were examined by quantitative bacterial counting using the blotting-paper strip method (Leigh \& Williams, 1964) and semi-quantitative white cell counts were carried out on a centrifuged deposit of the specimen.

Peritoneal dialysis fluid was cultured by plating a loopful of the centrifuged deposit. Specimens of sputum and wound swabs were examined by routine laboratory methods.

Bacterial growth was identified by routine laboratory tests and strains of Esch. coli, Proteus and $P s$. aeruginosa were further identified serologically.

Preliminary tests for antibiotic sensitivity were carried out using blotting paper discs impregnated with $10 \mu \mathrm{g}$ of gentamicin and $100 \mu \mathrm{g}$ of carbenicillin. The minimal inhibitory concentrations (MIC) of gentamicin and carbenicillin were estimated using a tube dilution method with an inoculum of approximately 100,000 organisms $/ \mathrm{ml}$.

TABLE 2. Causative organisms and site of infection

\begin{tabular}{|c|c|c|c|c|c|c|}
\hline Organisms & & Total & $\begin{array}{c}\text { Urinary } \\
\text { tract }\end{array}$ & Peritoneum & Lung & Wound \\
\hline Ps. aeruginosa & $\begin{array}{l}\mathrm{G} \\
\mathrm{C}\end{array}$ & $\begin{array}{l}14 \\
16\end{array}$ & $\begin{array}{l}6 \\
7\end{array}$ & $\begin{array}{l}7 \\
4\end{array}$ & $\begin{array}{l}1 \\
3\end{array}$ & $\overline{2}$ \\
\hline Esch. coli & $\begin{array}{l}\mathrm{G} \\
\mathrm{C}\end{array}$ & $\begin{array}{l}8 \\
5\end{array}$ & $\begin{array}{l}5 \\
2\end{array}$ & $\begin{array}{l}3 \\
2\end{array}$ & - & $\overline{1}$ \\
\hline Proteus spp. & $\begin{array}{l}\mathrm{G} \\
\mathrm{C}\end{array}$ & $\begin{array}{l}9 \\
2\end{array}$ & $\begin{array}{l}4 \\
2\end{array}$ & $\begin{array}{r}4 \\
--\end{array}$ & - & 1 \\
\hline Klebsiella spp. & $\begin{array}{l}\mathrm{G} \\
\mathrm{C}\end{array}$ & -5 & $\begin{array}{r}4 \\
-\end{array}$ & - & - & - \\
\hline Others* & $\begin{array}{l}\mathrm{G} \\
\mathrm{C}\end{array}$ & $\begin{array}{l}3 \\
4\end{array}$ & - & $\begin{array}{l}3 \\
4\end{array}$ & - & - \\
\hline Total & $\stackrel{G}{C}$ & $\begin{array}{l}39 \\
27\end{array}$ & $\begin{array}{l}19 \\
11\end{array}$ & $\begin{array}{l}18 \\
10\end{array}$ & $\begin{array}{l}1 \\
3\end{array}$ & $\begin{array}{l}1 \\
3\end{array}$ \\
\hline
\end{tabular}

$\mathrm{G}$, Gentamicin; C, carbenicillin.

* Acinetobacter anitratum 2; Alkaligenes spp, 4; Mima polymorpha, 1. 
TABLE 3. Sensitivity to gentamicin of Gram-negative bacilli isolated from infections in patients after transplantation

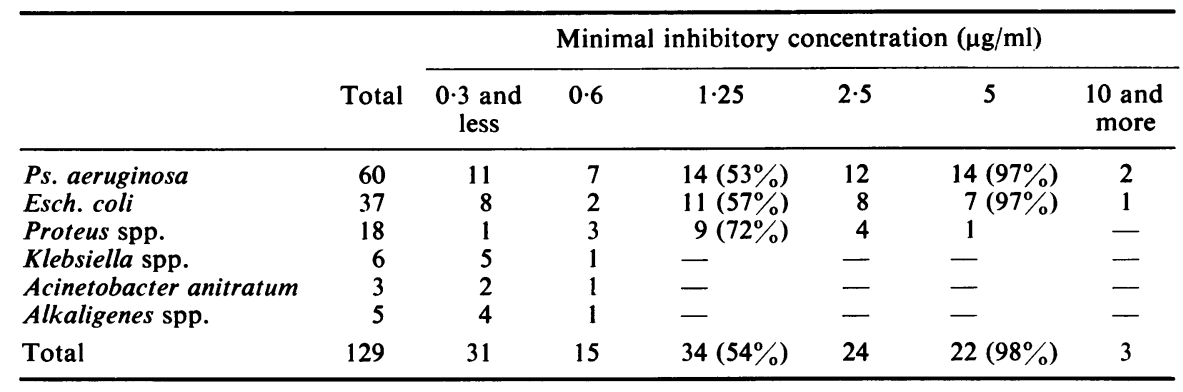

TABLE 4. Sensitivity to carbenicillin of Gram-negative bacilli isolated from infections in patients before and after renal transplantation

\begin{tabular}{|c|c|c|c|c|c|c|c|c|c|}
\hline & \multirow[b]{2}{*}{ Total } & \multicolumn{8}{|c|}{ Minimal inhibitory concentration $(\mu \mathrm{g} / \mathrm{ml})$} \\
\hline & & $\begin{array}{c}1.5 \text { and } \\
\text { less }\end{array}$ & 3 & 6 & $12 \cdot 5$ & 25 & 50 & 100 & $\begin{array}{l}200 \text { and } \\
\text { over }\end{array}$ \\
\hline Ps. aeruginosa & 55 & - & - & 3 & 6 & $9(33 \%)$ & 14 & $12(80 \%)$ & 11 \\
\hline Esch. coli & 27 & 3 & 2 & 4 & 9 & $3(77 \%)$ & - & 1 & 5 \\
\hline Proteus spp. & 13 & 7 & 1 & - & 1 & $3(97 \%)$ & - & - & 1 \\
\hline Klebsiella spp. & 8 & - & - & - & - & - & - & - & 8 \\
\hline Acinetobacter anitratum & 3 & 3 & - & - & - & - & - & - & - \\
\hline Alkaligenes spp. & 5 & - & - & 1 & 3 & 1 & - & - & - \\
\hline Total & 111 & 13 & 3 & 8 & 19 & $16(54 \%)$ & 14 & $13(77 \%)$ & 25 \\
\hline
\end{tabular}

\section{Serum and urine levels}

Serum and urine samples were taken from the majority of patients treated and the levels of gentamicin and carbenicillin were determined using a plate assay technique. The indicator organisms were for gentamicin a strain of Klebsiella edwardsii var atlanta and for carbenicillin the 'Ellsworth' strain of Ps. aeruginosa.

\section{Treatment}

In urinary tract infections and tissue infections treatment was prescribed for 7 days in the first instance and with gentamicin was according to the weight of the patient $(1.0 \mathrm{mg} / \mathrm{kg} / \mathrm{day}$ in divided doses). This dose was increased to $1.5 \mathrm{mg} / \mathrm{kg} /$ day in severe infections. In peritoneal infections gentamicin was only given intraperitoneally and was added to the dialysis fluid to give a final concentration of 10 or $25 \mu \mathrm{g} / \mathrm{ml}$.

Carbenicillin was usually given in a dose of $1 \mathrm{~g}$ intramuscularly every $6 \mathrm{hr}$ although in severe infections this was increased to $2 \mathrm{~g}$ or an intravenous infusion of $15-20 \mathrm{~g}$ a day given. In peritoneal infections carbenicillin was added to the dialysis fluid to give a final concentration of $100 \mu \mathrm{g} / \mathrm{ml}$. Intramuscular therapy was frequently given in addition to local therapy in peritoneal infections.

\section{Criterion of cure}

In urinary tract infections treatment was considered successful when the urine was sterile after treatment and 6 weeks later. Relapse of the infection due to the same organism was considered a failure of treatment but reinfection due to a different organism was not. In lung infections treatment was considered successful when the sputum became mucoid in nature and white cells and organisms disappeared from the film and culture. In peritoneal infections the total disappearance of the organisms from the dialysate was accepted as a cure. In patients who died soon after stopping treatment the infection was considered eradicated if no post-mortem cultures yielded the infecting organism.

\section{Results}

Sensitivity of Gram-negative bacilli to gentamicin and carbenicillin

The distribution of the minimal inhibitory concentrations of gentamicin and carbenicillin for Gram-negative bacilli are shown in Tables 3 and 4.

Fifty-three per cent of the strains of Ps. aeruginosa and $57 \%$ of Esch. coli were sensitive to $1.25 \mu \mathrm{g} / \mathrm{ml}$ or less of gentamicin and $97 \%$ of both species were inhibited by $5 \mu \mathrm{g} / \mathrm{ml}$. Only two strains of Ps. aeruginosa and one strain of Esch. coli were resistant to 
TABLE 5. Results of treatment of urinary tract infections

\begin{tabular}{|c|c|c|c|c|c|c|}
\hline & \multicolumn{3}{|c|}{ Gentamicin } & \multicolumn{3}{|c|}{ Carbenicillin } \\
\hline & No. & Cure & Reinfection & No. & Cure & Reinfection \\
\hline $\begin{array}{l}\text { Ps. aeruginosa } \\
\text { Esch. coli } \\
\text { Proteus spp. } \\
\text { Klebsiella spp. }\end{array}$ & $\begin{array}{l}6 \\
5 \\
4 \\
4\end{array}$ & $\begin{array}{l}2(33 \%) \\
4(80 \%) \\
2 \\
2\end{array}$ & $\begin{array}{l}1(50 \%) \\
3(75 \%) \\
1 \\
2\end{array}$ & $\begin{array}{r}7 \\
2 \\
2 \\
-\end{array}$ & $\begin{array}{l}5(71 \%) \\
1 \\
-\end{array}$ & $\begin{array}{l}3(60 \%) \\
- \\
-\end{array}$ \\
\hline Total & 19 & $10(53 \%)$ & $7(70 \%)$ & 11 & $6(54 \%)$ & $3(50 \%)$ \\
\hline
\end{tabular}

$10 \mu \mathrm{g} / \mathrm{ml}$ or more. Proteus strains were more sensitive, $72 \%$ being inhibited by $1.25 \mu \mathrm{g} / \mathrm{ml}$. All the strains of Klebsiella, Alkaligenes and Acinetobacter were sensitive to $0.6 \mu \mathrm{g} / \mathrm{ml}$ (Table 3 ).

Proteus strains were the organisms most sensitive to carbenicillin, $61 \%$ being inhibited by less than $12.5 \mu \mathrm{g} / \mathrm{ml}$, and $97 \%$ by $25 \mu \mathrm{g} / \mathrm{ml}$. Strains of Esch. coli were less sensitive, only $33 \%$ being inhibited by less than $12.5 \mu \mathrm{g} / \mathrm{ml} ; 77 \%$ of strains, however, were sensitive to $25 \mu \mathrm{g} / \mathrm{ml}$. Ps. aeruginosa strains were more resistant, only $33 \%$ being inhibited by $25 \mu \mathrm{g} / \mathrm{ml}$ but $80 \%$ were sensitive to $100 \mu \mathrm{g} / \mathrm{ml}$. All the strains of Klebsiella were resistant but the strains of Acinetobacter and Alkaligenes were sensitive to $25 \mu \mathrm{g} / \mathrm{ml}$ (Table 4).

The bactericidal concentration of gentamicin was usually only twice as great as the inhibitory concentration but with carbenicillin it was more variable and was sometimes as great as eight times the inhibitory concentration.

\section{Serum and urine levels}

The serum levels of gentamicin when measured were generally greater than the MIC of the infecting organism and no failure of treatment was obviously associated with a poor serum concentration. Urine levels were usually high even where the renal function was poor and were frequently fifty times greater than the MIC of the infecting organism. Diffusion of gentamicin across the peritoneal membrane was measured in four patients and considerable variation was found. Serum concentrations of between 3 and $14 \mu \mathrm{g} / \mathrm{ml}$ were found $4-6 \mathrm{hr}$ after dialysis with a concentration of $25 \mu \mathrm{g} / \mathrm{ml}$.

Serum levels of carbenicillin were often high in patients with poor renal function after transplantation and concentrations of between 100 and 200 $\mu \mathrm{g} / \mathrm{ml}$ were seen. Urine levels were usually between 500 and $2000 \mu \mathrm{g} / \mathrm{ml}$. Diffusion of carbenicillin across the peritoneal membrane was not measured.

\section{Treatment}

The results of treating urinary tract infections with gentamicin and carbenicillin are shown in Table 5. The overall cure-rates were similar with both antibiotics, being 53 and $54 \%$, respectively. The end-result of treatment, however, was disappointing, as of the ten cures with gentamicin 7 $(70 \%)$ became reinfected with a different organism after stopping treatment. The reinfection rate with carbenicillin treatment was $50 \%$.

In peritoneal and tissue infections there was little difference in the overall cure rates with the two antibiotics (Table 6).

TABLE 6. Results of treatment in peritoneal and tissue infections

\begin{tabular}{|c|c|c|c|c|}
\hline & \multicolumn{2}{|c|}{ Gentamicin } & \multicolumn{2}{|c|}{ Carbenicillin } \\
\hline & No. & Cure & No. & Cure \\
\hline Ps. aeruginosa & 8 & $4(50 \%)$ & 9 & $5(55 \%)$ \\
\hline Esch. coli & 3 & 3 & 3 & \\
\hline Proteus spp. & 5 & 2 & - & - \\
\hline Klebsiella spp. & 1 & - & - & - \\
\hline $\begin{array}{l}\text { Other Gram-negative } \\
\text { bacilli }\end{array}$ & 3 & 1 & 4 & 3 \\
\hline Total & 20 & $10(50 \%)$ & 16 & $10(62 \%)$ \\
\hline
\end{tabular}

The results of treating infections complicated by bacteraemia were poor, only one of the five treated with gentamicin and one of the four treated with carbenicillin responded to treatment.

When the results of treatment were compared in 'Simple' and 'Complicated' infections it was found that a cure rate of over $70 \%$ could be expected with both antibiotics in 'Simple' infections (Table 7) but

TABLE 7. Results of treatment according to the severity of the infection

\begin{tabular}{lcccccccrr}
\hline & & \multicolumn{3}{c}{ Simple } & & \multicolumn{3}{c}{ Complicated } \\
\cline { 3 - 5 } \cline { 7 - 9 } & Total & No. & Cure & Reinfection & No. & Cure & Reinfection \\
\hline Gentamicin & 39 & 7 & $5(71 \%)$ & - & & 32 & $15(47 \%)$ & $9(60 \%)$ \\
Carbenicillin & 27 & 13 & $10(77 \%)$ & - & & 14 & $6(43 \%)$ & $5(83 \%)$ \\
Total & 66 & 20 & $15(75 \%)$ & - & & 46 & $21(46 \%)$ & $14(67 \%)$ \\
\hline
\end{tabular}


in 'Complicated' infections the cure rate fell considerably to $47 \%$ for gentamicin and $43 \%$ for carbenicillin. Reinfections were not seen in simple infections but occurred in nine complicated infections treated with gentamicin and five with carbenicillin.

\section{Side and toxic effects}

No local effects of intramuscular injections of gentamicin were seen and there was no pain on dialysis when it was infused at a concentration of $25 \mu \mathrm{g} / \mathrm{ml}$.

Only one patient showed an acute toxic effect after gentamicin therapy, although eleven patients died within a few days of stopping therapy and therefore could not be assessed.

The one patient who showed toxic effects had a history of blurred vision due to hypertension but no past history of defective hearing or vestibular function. Gentamicin was prescribed for a peritonitis and septicaemia caused by Ps. aeruginosa, and was given both intramuscularly $(25 \mathrm{mg}$ b.d.) and in the dialysing fluid $(25 \mu \mathrm{g} / \mathrm{ml})$. The treatment was successful after two courses of 5 and 10 days. The loss of vestibular function became apparent 2 weeks later when he was able to walk about the ward. Two series of caloric tests showed complete loss of vestibular function. This man is now alive and well following successful cadaver renal transplantation and has compensated completely for his vestibular defect.

Pain on injection was a troublesome symptom to many patients on carbenicillin treatment. The addition of procaine to the injection provided some relief. No toxic effects of carbenicillin were observed despite intravenous infusion of large amounts.

\section{Reasons for failure of treatment}

Although the two groups of patients were similar in many respects the infections in the gentamicin group were more complicated (Table 1). Of the thirty-nine gentamicin-treated infections thirty-two were associated with severe complications such as a poorly functioning renal transplant, ureteric necrosis or recurrent infections and previous antibiotic therapy had failed in thirty-seven infections. In the twenty-seven carbenicillin-treated infections only fourteen were associated with complications and nineteen had failed previous antibiotic therapy.

The main reason for failure in nineteen of the gentamicin-treated infections was probably due to the antibiotic failing to reach the primary focus of infection. In eleven cases there was poor function of the renal transplant and abscess formation in the kidney or perinephric region was common. In five of the peritoneal infections dense adhesions were present. In two cases the course of treatment was probably too short as a second course resulted in eradication of the infection. In only one case was no reason found.

Of the eleven failures with carbenicillin three were due to a resistant organism and an effective blood level could not be attained. In three cases of lung infection the sputum levels were low $(6 \cdot 25 \mu \mathrm{g} / \mathrm{ml})$ and even though there was clinical response to treatment the infecting organisms were not eradicated. In only two cases was there either poor renal function or peritoneal adhesions and in three cases no reason could be found.

\section{Discussion}

Infections caused by Ps. aeruginosa and the resistant strains of the Enterobacteriaciae are usually associated with underlying abnormalities of varying severity and occur in patients who have had multiple courses of antibiotic therapy. Most of the patients in this study had undergone human cadaveric renal transplantation and were receiving steroid and immunosuppressive therapy and a few patients had severe post-operative complications such as ureteric necrosis or renal tissue infection. Many of the patients not transplanted had had recurrent episodes of infection in the peritoneal cavity and adhesions were present. Under these conditions the development of infection presents a severe test to the efficacy of any chemotherapeutic agent.

Laboratory tests with gentamicin showed that over $90 \%$ of Gram-negative bacilli isolated from renal transplant patients were sensitive to $5 \mu \mathrm{g} / \mathrm{ml}$ (Table 3) and this finding confirms the reports of other workers (Bulger, Sidell \& Kirby, 1963; Barber \& Waterworth, 1966; Jones \& Lowbury, 1967; Jackson, 1967).

Few studies have reported the sensitivity of Gramnegative bacilli to carbenicillin. In this study strains of Proteus were the most sensitive organisms, 97\% being inhibited by $25 \mu \mathrm{g} / \mathrm{ml}$ (Table 4). Strains of $P s$. aeruginosa were more resistant but $80 \%$ were inhibited by $100 \mu \mathrm{g} / \mathrm{ml}$. These results agree with those reported by Brumfitt et al. (1967) and Jones \& Lowbury (1967) but not with Knudsen et al. (1967) who found that $88 \%$ of clinical isolates were sensitive to $50 \mu \mathrm{g} / \mathrm{ml}$.

The results of sensitivity tests on Gram-negative bacilli causing infections in renal-transplant patients show that these are not a special group of highly resistant organisms but are the common organisms in the community. Under certain circumstances, however, sensitive organisms, e.g. Acinetobacter species and Alkaligenes species which rarely cause infection in the general population, can establish themselves in these highly susceptible patients.

Although acquired resistance to gentamicin has been found in vitro (Barber \& Waterworth, 1966) 
and in vivo (Darrell \& Waterworth, 1967; Jones \& Lowbury, 1967) it was not a cause of failure of treatment in patients in this study. No acquired resistance was shown to occur in patients treated with carbenicillin.

The results of treatment of infections complicated by severe underlying abnormalities will depend not only on the serum level of antibiotic but the ability of the antibiotic to diffuse into the primary focus of infection.

The levels of gentamicin and carbenicillin were not regularly determined but where estimated the antibiotic concentrations were found to exceed the MIC of the infecting organisms with the exception of the carbenicillin-resistant strains (MIC over 200 $\mu \mathrm{g} / \mathrm{ml}$ ). There is no doubt that in many cases the serum level does not represent the relevant tissue level especially where the infection is situated in the perinephric or retropubic space which has a poor blood supply so that many failures may have been due to a low concentration of antibiotic reaching the primary focus of infection.

The end-results of treatment of urinary tract infections with gentamicin and carbenicillin were poor as the rate of reinfection was high and only six out of the thirty infections did not relapse (Table 5).

Although a cure rate of over $70 \%$ was achieved in all simple infections, the presence of an underlying abnormality was associated with a considerable reduction in this rate (Table 7 ).

In this study only one case of acute toxicity to gentamicin was seen but many patients died soon after stopping therapy and so the true incidence of toxicity could not be assessed.

The treatment of Gram-negative infections in renal-transplant patients is difficult especially where the infecting organism is Ps. aeruginosa. Even where the infection appears uncomplicated the effect of immunosuppressive therapy on the patient and the infecting organisms is unknown and may possibly influence the outcome of treatment. The findings in this study suggest that immunosuppressive therapy does not primarily affect the outcome of treatment although it may possibly aid bacterial invasion of the tissues, while inadequate control of immunosuppression, leading to deterioration in the function of the renal transplant, certainly reduces the cure rate.

Serious infection, especially when accompanied by bacteraemia, in patients after renal transplantation has rarely responded to antibiotic therapy (Mowbray et al., 1965) although Murdoch \& Geddes (1967) have reported success with polymyxins in the treatment of Ps. aeruginosa septicaemia in patients with chronic urinary tract infections.

Fifty-nine per cent of the patients in this study died, and death was directly due to infection in
$77 \%$ of the patients after transplantation and $71 \%$ before transplantation. All deaths were associated with severe complications.

With the introduction of gentamicin and carbenicillin, two new antibiotics are available for the treatment of Gram-negative infections. Whilst carbenicillin is free of serious side-effects many organisms are resistant to the serum levels achieved on intramuscular therapy although higher levels can be attained by intravenous infusion. Gentamicin, however, has a wider spectrum of bacterial action which includes Gram-positive cocci but toxic effects to the vestibular branch of the eighth nerve can occur

In this study carbenicillin was used as the primary treatment for infections due to organisms sensitive to both antibiotics. Gentamicin was given for carbenicillin failures and where the organism was resistant to carbenicillin. It is important that serum levels are monitored in all serious infections and this is especially so when gentamicin is used. The synergism reported between carbenicillin and gentamicin may overcome the serious toxic effects of gentamicin as a very much smaller dose is needed. Synergism, however, is not invariably present and laboratory tests should always be carried out. In infections associated with bacteraemia it is probably advisable that both antibiotics are given.

The use of gentamicin and carbenicillin in infections in patients who have had cadaver renal transplantation has undoubtedly improved the chance of cure but complete success will ultimately depend on the accessibility of the primary focus of infection and the severity of the underlying abnormality.

\section{Acknowledgments}

I would like to thank Miss C. Whittaker for her assistance with the laboratory studies, and Professor W. S. Peart for allowing me to carry out the treatment study on his patients.

Supplies of gentamicin ('Cidomycin') were made available by Roussel Laboratories Ltd. Miss C. Whittaker was in receipt of a grant from the Wellcome Trust.

\section{References}

BArber, M. \& WATerworth, P.M. (1966) Activity of gentamicin against Pseudomonas and hospital staphylococci. Brit. med. J. 1, 203.

Brumfitt, W., Percival, A. \& Leigh, D.A. (1967) Clinical and laboratory studies with carbenicillin. A new penicillin active against Pseudomonas pyocyanea. Lancet, i, 1289.

Bulger, R.J., Sidell, S. \& Kirby, W.M.M. (1963) Laboratory and clinical studies of gentamicin. A new broadspectrum antibiotic. Ann. intern. med. 59, 593.

Darrell, J.H. \& Waterworth, P.M. (1967) Dosage of gentamicin for Pseudomonas infections. Brit. med. J. 2, 535.

JACKSON, G.G. (1967) Laboratory and clinical investigation of gentamicin. 1st International Symposium on 'Gentamicin', Paris, p. 62. Essex Chemie AG, Lucerne. 
Jones, R J. \& Lowbury, E.J.L. (1967) Prophylaxis and therapy for Pseudomonas aeruginosa infection with carbenicillin and with gentamicin. Brit. med. J. 3, 79.

KNudSen, E.T., Rolinson, G.N. \& Sutherland, R (1967) Carbenicillin: a new semisynthetic penicillin active against Pseudomonas pyocyanea. Brit. med. J. 3, 75.

Leigh, D.A. \& Williams, J.D. (1964) Method for the detection of significant bacteriuria in large groups of patients. J. clin. Path. 17, 498.

Mowbray, J.F., Cohen S.L., Doak, P.B., Kenyon J.R., Owen, K., Percival, A., Porter, K.A \& Peart, W.S. (1965) Human cadaveric renal transplantation. Report of twenty cases. Brit. med. J. 2, 1387.
Murdoch, J.McC. \& Geddes, A.M. (1967) Carbenicillin (letter). Lancet, ii, 46.

Rosselet, J.P., Marquez, J., Meseck, E., Murawski, A., Hamdam, A., Joyner, C., Schmidt, R., Migliore, D. \& HeRzoG, H.L. (1963) Isolation, purification, and characterization of gentamicin. Antimicrobial Agents and Chemotherapy, p. 14.

Weinstein, M.J., Leudemann, G.M., Oden, E.M., Wagman, G.H., Rosselet, J.P., Marquez, J., Conigloo, C.T., Charnley, W., Herzog, H.L. \& Black, J. (1963) Gentamicin, a new antibiotic complex from Micromonospora. J. med. Chem. 6, 463. 